\title{
Biodistribution and Radiation Dosimetry of 99mTc-HMPAO-Labeled Monocytes in Patients with Rheumatoid Arthritis
}

\author{
Roelof J. Bennink ${ }^{1}$, Rogier M. Thurlings ${ }^{2}$, Formijn J. van Hemert ${ }^{1}$, Carlijn Voermans $^{3}$, Serge E. Dohmen ${ }^{3}$, \\ Berthe L. van Eck-Smit ${ }^{1}$, Paul P. Tak ${ }^{2}$, and Ellinor Busemann-Sokole ${ }^{1}$ \\ ${ }^{1}$ Department of Nuclear Medicine, Academic Medical Center, University of Amsterdam, Amsterdam, The Netherlands; ${ }^{2}$ Department of \\ Clinical Immunology and Rheumatology, Academic Medical Center, University of Amsterdam, Amsterdam, The Netherlands; and \\ ${ }^{3}$ Department of Experimental Immunohematology, Sanquin Research, Amsterdam, The Netherlands
}

Rheumatoid arthritis (RA) involves the accumulation of monocytederived macrophages in the affected synovial tissue. This process of cell migration could be portrayed scintigraphically to monitor noninvasively the effects of therapy on the progress of the disease. For this purpose, labeling of purified autologous

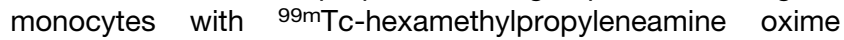
(99mTc-HMPAO) at very high specific radioactivity has recently been developed. The aim of this study was to assess the biodistribution and radiation dosimetry of 99mTc-HMPAO-labeled monocytes in adult patients with RA. Methods: In 8 patients with RA, monocytes were isolated from $100 \mathrm{~mL}$ of blood and labeled with ${ }^{99 m}$ Tc-HMPAO to a yield of $10 \mathrm{~Bq} /$ cell. Multiple whole-body scans were performed up to $20 \mathrm{~h}$ after reinjection

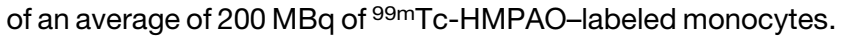
Urine and blood samples were collected. The fraction of administered activity in 7 source organs was quantified from the attenuation-corrected geometric mean counts in conjugate views. Radiation-absorbed doses were estimated with OLINDA/EXM software. Results: Autologous monocytes labeled with ${ }^{99 m T c-}$ HMPAO at high intracellular yields showed in vivo kinetics comparable with labeled leukocytes, with initial trapping in the lungs followed by distribution into the liver, spleen, and bone marrow. The radiation-absorbed estimates for 99mTc-HMPAO-labeled monocytes were comparable with those for 99mTc-HMPAOlabeled mixed white blood cells, with an effective dose of 0.011 $\mathrm{mSv} / \mathrm{MBq}$. Conclusion: 99mTc-HMPAO-labeled monocytes have biodistribution and radiation dosimetry similar to those of $99 \mathrm{~m}$ Tc-HMPAO-labeled mixed white blood cells and might therefore be used for in vivo monitoring of immunomodulating therapy in patients with RA.

Key Words: joint/muscle; radiobiology/dosimetry; radiopharmaceuticals; biodistribution; monocytes; rheumatoid arthritis

J Nucl Med 2008; 49:1380-1385

DOI: 10.2967/jnumed.108.051755

Received Feb. 13, 2008; revision accepted Apr. 14, 2008.

For correspondence or reprints contact: Roelof J. Bennink, Academic Medical Center, Department of Nuclear Medicine F2-235, Meibergdreef 9,

1105 AZ Amsterdam, The Netherlands.

E-mail: r.bennink@amc.uva.nl

COPYRIGHT @ 2008 by the Society of Nuclear Medicine, Inc.
$\mathbf{R}$ heumatoid arthritis (RA) is a chronic inflammatory disease affecting synovial tissue in multiple joints. Monocytederived macrophage cells accumulate in the inflamed synovium and thereby contribute to the perpetuation of inflammation and destruction of the affected joints (1). Reduced migration of inflammatory cells such as monocytes or macrophages into the synovial compartment or a decrease in the retention of these cells at the site of inflammation may be attained by treatment of patients with antibodies against tumor necrosis factor- $\alpha$ (TNF- $\alpha)(2)$ or perhaps with chemokine receptor antagonists (3).

For noninvasive monitoring of treatment, migration of cells toward sites of inflammation in vivo can be portrayed scintigraphically after radiolabeling of the cells in vitro with ${ }^{99 m}$ Tc-labeled hexamethylpropyleneamine oxime (HMPAO). Therefore, labeling of purified autologous monocytes with ${ }^{99 \mathrm{~m}} \mathrm{Tc}-\mathrm{HMPAO}$ at very high specific radioactivity has recently been developed (4).

In this study, the biodistribution and radiation dosimetry of 99mTc-HMPAO-labeled monocytes were assessed in adult patients with RA.

\section{MATERIALS AND METHODS}

\section{Patients}

Radiation dosimetry measurements were obtained in 8 patients with RA (4 women and 4 men) with active disease despite methotrexate treatment (mean age, $52 \mathrm{y}$; age range, 39-58 y). The study protocol was approved by the Medical Ethics Committee of the Academic Medical Center (AMC) of the University of Amsterdam. Written informed consent was obtained before patient participation.

\section{Monocyte Separation and Labeling}

Peripheral venous blood $(100 \mathrm{~mL})$ was drawn from patients via an 18-gauge intravenous line into a sterile bottle containing $15 \mathrm{~mL}$ of acid citrate dextrose (ACD; disodium citrate $1.5 \mathrm{H}_{2} \mathrm{O}, 3 \%$, w/v, in glucose $1 \mathrm{H}_{2} \mathrm{O}, 2.5 \%$, w/v) and transported to the Laboratory for Stem Cell Transplantation, Sanquin Research Amsterdam. Subsequently, autologous CD14-positive (CD14+) monocytes were 
TABLE 1

Patient Characteristics

\begin{tabular}{lc}
\hline \multicolumn{1}{c}{ Characteristic } & Data \\
\hline Sex & Men, 4 ; women, 4 \\
Age $(\mathrm{y})$ & $52.3 \pm 5.7$ \\
Blood volume drawn $(\mathrm{mL})$ & $110.7 \pm 18.7$ \\
Number WBCs before MACS $\left(\times 10^{6}\right)$ & $764 \pm 165$ \\
\% CD14+ before MACS & $6.59 \pm 1.78$ \\
Number WBC after MACS $\left(\times 10^{6}\right)$ & $25.38 \pm 8.52$ \\
$\%$ CD14+ after MACS & $92.12 \pm 4.17$ \\
Labeling yield $(\mathrm{Bq} / \mathrm{cell})$ & $10.83 \pm 4.23$ \\
Injected dose $(\mathrm{MBq})$ & $230.2 \pm 109.2$ \\
\hline
\end{tabular}

isolated from the peripheral blood by a positive-selection procedure of a magnetic-activated cell sorting (MACS) device (CliniMACS; Miltenyi Biotech), according to the manufacturer's protocol. After the selection procedure, the percentage of $\mathrm{CD} 14+, \mathrm{CD} 3+$, and CD66 + cells was determined by fluorescence-activated cell sorting analysis. The CD14+-enriched cells were resuspended in $10 \mathrm{~mL}$ of buffer containing $0.9 \%(\mathrm{w} / \mathrm{v})$ sodium chloride $(\mathrm{NaCl})(\mathrm{BI}$ Braun Medical SA), 20\% (w/v) human serum albumin (Sanquin CLB Products Division), and 3.8\% (w/v) trisodium citrate (TSC; NVI; similar to $\mathrm{ACD}$ ) ( $\mathrm{NaCl} /$ human serum albumin/TSC). The CD14+enriched cells were then transported to the AMC for labeling. The procedure was professionally approved for the radiopharmaceutical objective of the product.

\section{Radiopharmaceuticals}

Exametazime (Ceretec, RVG16226; Amersham International plc) was supplied as a ready-for-labeling kit (GE Healthcare B.V.). ${ }^{99 \mathrm{~m} T c-p e r t e c h n e t a t e ~ w a s ~ o b t a i n e d ~ f r o m ~ a ~}{ }^{99} \mathrm{Mo}-$ carrying FM generator (Ultratechnekov, DRN 4329; Tyco Healthcare, Mallinckrodt Medical) and was eluted according to the manufacturer's instructions. Radiochemical purity control assays were performed using instant thin-layer chromatography silica gel strips with a mobile phase of $0.9 \% \mathrm{NaCl}(5)$. Radiolabeling of cells was performed as described earlier (4). Briefly, the cells were centrifuged $(200 g$ for $10 \mathrm{~min}$ at room temperature). Subsequently, freshly prepared
${ }^{99 m}$ Tc-HMPAO of very high specific activity in a volume as small as possible was added to the monocyte cell pellet and incubated for $10 \mathrm{~min}$. The excess of the ${ }^{99 \mathrm{~m}} \mathrm{Tc}-\mathrm{HMPAO}$ and its decomposition products were diluted from 2 to $50 \mathrm{~mL}$ and subsequently removed from the cell pellet after centrifugation. The radiolabeled monocytes were resuspended in $0.9 \% \mathrm{NaCl}$, and after calibration $(\sim 200 \mathrm{MBq} /$ $20 \times 10^{6}$ cells) they were ready for infusion into the patient.

\section{Study Protocol}

All images were obtained with a dual-head scintillation camera (E.cam; Siemens) fitted with low-energy all-purpose collimators. A $15 \%$ energy window was used for both ${ }^{99 \mathrm{~m}} \mathrm{Tc}$ and ${ }^{57} \mathrm{Co}$ imaging. All whole-body scans, both emission and transmission, were performed in anterior and posterior views with a scan speed of $8 \mathrm{~cm} / \mathrm{min}$. The same radionuclide dose calibrator was used for all radioactivity measurements.

Whole-Body Transmission Imaging. For attenuation correction, a dual-head whole-body transmission scan was performed on each patient before injection of ${ }^{99 \mathrm{~m}} \mathrm{Tc}-\mathrm{HMPAO}-$ labeled monocytes. A $300-\mathrm{MBq}{ }^{57} \mathrm{Co}$ flood source was placed on the lower detector head. Thus, the upper detector head measured transmission through the patient and imaging table in the anterior view, whereas the lower detector measured the counts in air.

Whole-Body Emission Scans. For each patient, a series of 5 whole-body emission scans was performed at 10 min and 1, 2, 3, and $20 \mathrm{~h}$ after injection of ${ }^{99 \mathrm{~m} T c-H M P A O-l a b e l e d ~ m o n o c y t e s . ~}$ The stability of these measurements over this total measurement period was monitored by including a vial containing $2 \mathrm{MBq}$ of ${ }^{99 \mathrm{~m}} \mathrm{Tc}$-pertechnetate placed between the lower legs of the patient during each emission scan.

The equality of the sensitivity of anterior and posterior collimated detectors for ${ }^{99 \mathrm{~m}} \mathrm{Tc}$ was verified, according to the National Electrical Manufacturers Association NU-1 protocol (6), from static images obtained of a calibrated amount of ${ }^{99 \mathrm{~m}} \mathrm{Tc}$ activity in a Petri dish placed at $10 \mathrm{~cm}$ below each detector.

The calibration factor applied to convert whole-body emission counts to $\mathrm{MBq}$ was measured and monitored for the anterior detector head. This factor was obtained from a whole-body scan of the Petri dish placed on the imaging table, containing a calibrated amount of ${ }^{99 \mathrm{~m} T c}(25 \mathrm{MBq})$. The net counts were obtained from a

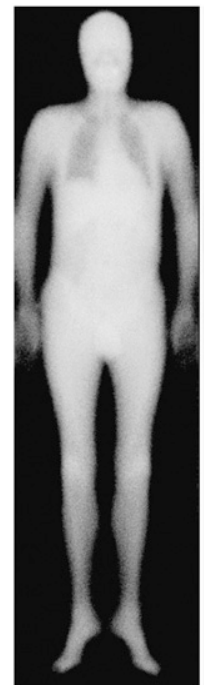

Trans

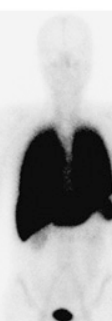

1

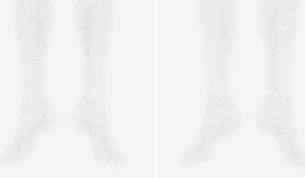

$10 \mathrm{~min}$

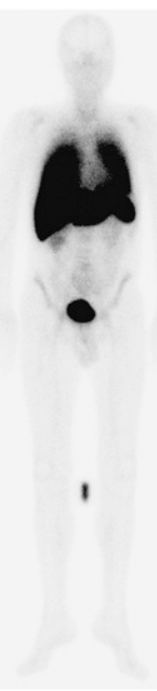

$1 \mathrm{~h}$

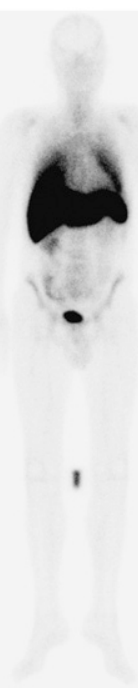

$2 \mathrm{~h}$

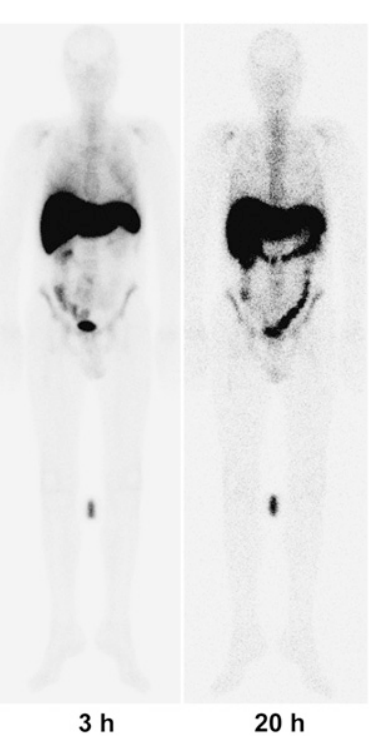

FIGURE 1. 48-y-old male patient with RA. Anterior whole-body transmission (Trans) scan performed before reinjection of $99 \mathrm{mTc}$-HMPAO-labeled monocytes, and anterior whole-body emission images obtained $10 \mathrm{~min}$ and $1,2,3$, and $20 \mathrm{~h}$ after reinjection of 99mTc-HMPAOlabeled monocytes. In this patient, first voiding period after reinjection took place after 1-h whole-body emission scan. Reference source is placed just below knees. 


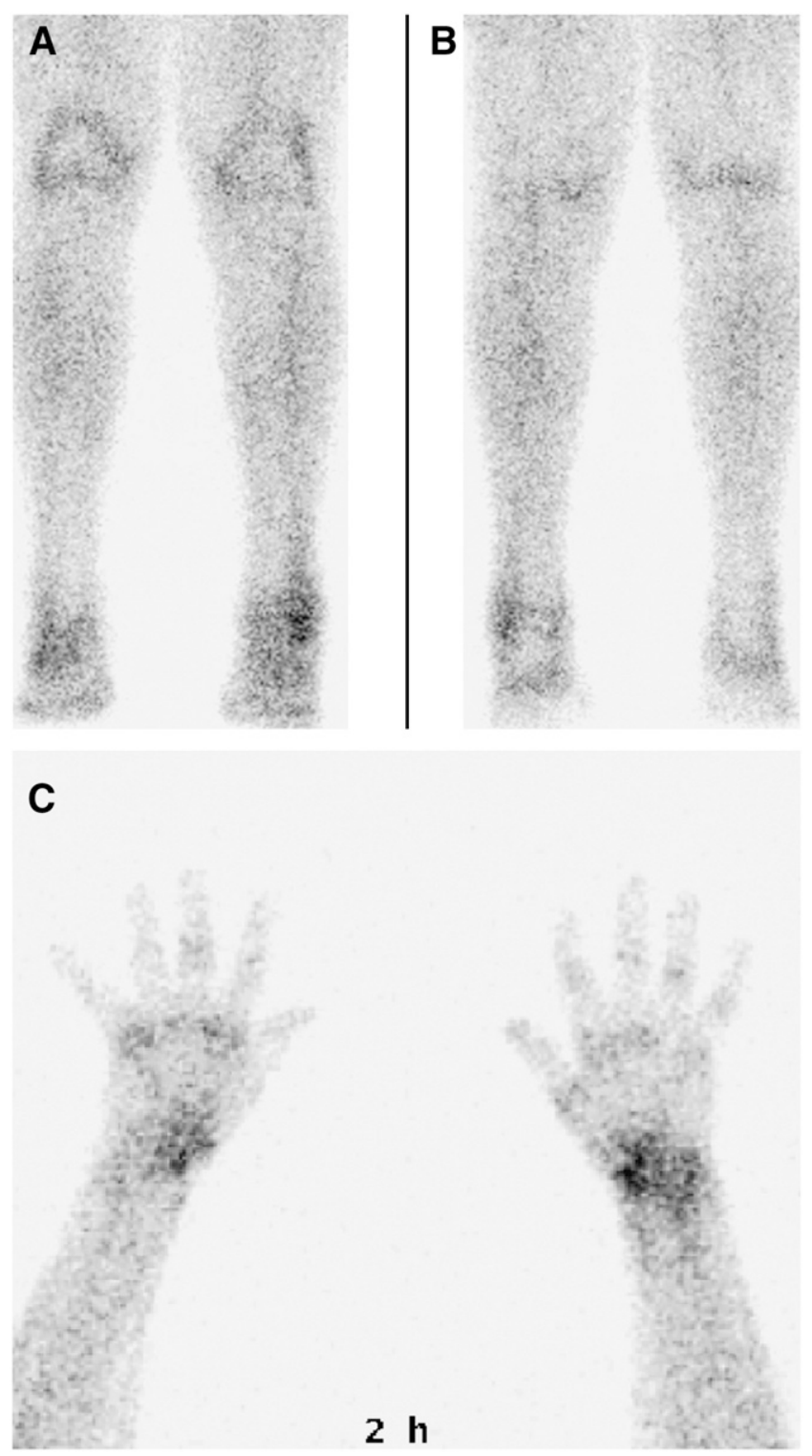

FIGURE 2. Anterior (A) and posterior (B) images of knees and ankles of $41-y$-old female patient. Palmar image (C) of wrists and hands of 54-y-old female patient with active RA. Images show markedly elevated uptake of $99 \mathrm{mTC}-\mathrm{HMPAO}-\mathrm{labeled}$ monocytes in both knees, left ankle, both wrists, and multiple metacarpophalangeal and interphalangeal joints compatible with active inflammation.

circular region of interest (ROI) drawn over the Petri dish image and a copy of the circular ROI placed in a background region. The activity was calibrated to the actual time of scanning over the Petri dish. This calibration factor gave the conversion of counts to $\mathrm{MBq}$ measured in air, without absorption of the imaging pallet.

Blood and Urine. Blood samples were obtained just before each of the whole-body emission scans. Three duplicate 1-mL samples of blood were measured in a $\gamma$-sample changer (Packard), with an appropriate standard activity of ${ }^{99 \mathrm{~m}} \mathrm{Tc}$ to convert from counts to megabecquerels. The total amount of radioactivity in the blood was calculated using a total blood volume based on sex, individual body weight and height, and body surface area and expressed as a percentage of the injected dose of ${ }^{99 \mathrm{~m}} \mathrm{Tc}-\mathrm{HMPAO}-$ labeled monocytes (7-9).

Urine was collected to verify excretion as estimated from the whole-body scans. The urine was collected in 3 separate containers, corresponding to the separate collection periods of $0-2$, $2-3$, and $3-20 \mathrm{~h}$; the final urine collection of each period was made just before the whole-body scan at 2,3 , and $20 \mathrm{~h}$, respectively. The urine volume in each container was determined by the net weight of each urine container. Three duplicate 1-mL samples from each container were measured in the $\gamma$-sample changer, and the total urine activity was estimated using the total urine volume from each collection period.

\section{Whole-Body Scan Image Analysis}

For each patient, an anterior and posterior set of ROIs was created for the activity observed in the source organs of interest: liver, lungs, spleen, kidneys, 2-4 lumbar vertebrae (depending on visibility), thyroid, bladder, and intestines. In addition, ROIs were drawn over the total body. The anterior lung ROIs were obtained from the anterior transmission scan. Different background ROIs were also obtained and applied to the various organ ROIs: lateral below the liver (background correction for liver, kidneys, bladder, spleen, and intestines), lateral to lumbar vertebrae (background correction for bone marrow activity in lumbar vertebrae), arm (background correction for thyroid), and outside the body (background correction for whole body). The anterior and posterior ROIs mirrored each other. Once a set of anterior and posterior ROIs had been created, this set was applied to each emission whole-body scan and also the transmission scan. Adjustments were applied when necessary for a difference in the position of the patient. The counts and pixels in each ROI were obtained in each anterior and posterior image using a HERMES workstation (Nuclear Diagnostics).

For each emission whole-body scan, counts in the different source organ ROIs were corrected for their appropriate background counts, and geometric averages were calculated. These were corrected with the appropriate ${ }^{57} \mathrm{Co}$ attenuation correction factor (obtained from the square root of the ratio anterior counts per pixel divided by the posterior counts per pixel for the organ ROI in the transmission scan) and then finally converted to megabecquerels. To obtain biologic distribution data, a final decay correction was applied using the time between injected activity and the start of the whole-body scan, plus an extra $10 \mathrm{~min}$ as the decay time interval.

\section{Dosimetry}

The OLINDA/EXM software was used to obtain absorbed doses (10). This software includes a kinetic input module with exponential curve fitting of the input data for determining the number of disintegrations per unit of administered activity $(\mathrm{Bq}-\mathrm{h} / \mathrm{Bq})$ in each source organ. The number of disintegrations was thus obtained by applying an exponential fit of the second or third degree to the distribution data of each source organ. The whole-body retention data, whereby the geometric mean counts in the second scan were taken to be equivalent to $100 \%$ of injected activity, correlated with the amount of activity excreted in the urine. Because a considerable decrease in lung activity was observed between $10 \mathrm{~min}$ and $1 \mathrm{~h}$, the whole-body ROI counts at $1 \mathrm{~h}$ were used as the $100 \%$ of injected activity as the reference for calculating the total body distribution at each subsequent time point. The activity measured in the lumbar ROI was corrected to total marrow mass (11). The difference between total-body disintegrations and the sum of all source organ disintegrations, excluding the urinary bladder contents, was applied 
as a value for the remainder of body organs in OLINDA/EXM. The disintegrations for urinary bladder contents were based on the whole-body excretion and a 4-h voiding interval. The radiation dose estimates were calculated for each patient independently and then averaged for both male and female patients.

\section{RESULTS}

Patient characteristics are summarized in Table 1. After MACS enrichment, the mean percentage of CD14+ monocytes increased from $6.6 \%$ to $92.1 \%$. With a mean labeling yield of $10.83 \pm 4.23 \mathrm{~Bq} / \mathrm{cell}$, labeling of $25 \times 10^{6}$ cells resulted in an average injected dose of $230 \mathrm{MBq}$. The biodistribution of ${ }^{99 \mathrm{~m}} \mathrm{Tc}-\mathrm{HMPAO}-$ labeled monocytes on emission scintigraphy in a patient with RA at different time points after injection is illustrated in Figure 1. An intense uptake in the lungs at $10 \mathrm{~min}$, which decreased considerably by $1 \mathrm{~h}$, and intense tracer accumulation in the liver and spleen and moderate accumulation in the kidneys, bladder, and bone marrow was demonstrated. After $2 \mathrm{~h}$, major changes in distribution over time could no longer be observed, except for an increase in bowel activity. Simultaneously, accumulation of monocytes could be detected in large and small joints (Fig. 2).

The percentage of administered activity of ${ }^{99 \mathrm{~m}} \mathrm{Tc}-$ HMPAO-labeled monocytes in various body compartments over time is presented in Table 2 . The relative activity in the lungs decreased over time, whereas the relative activity in the liver and the spleen increased up to $3 \mathrm{~h}$ after reinjection. The relative activity of the kidneys and the bladder remained stable except for the bladder activity $1 \mathrm{~h}$ after reinjection; patients had been asked not to void until after completion of the 1-h whole-body scan. Bowel uptake appeared on the 3-h scan and reached on average $5.5 \%$ after $20 \mathrm{~h}$.

Table 3 gives the number of disintegrations (MBq-h/ $\mathrm{MBq}$ administered) for the different source organs. The highest values were found for the liver, red bone marrow, spleen, and lungs. Table 4 displays the averaged estimated absorbed doses for the OLINDA/EXM adult male and female patients for ${ }^{99 \mathrm{~m}} \mathrm{Tc}-\mathrm{HMPAO}-$ labeled monocytes. The organs that received the highest absorbed doses for ${ }^{99 \mathrm{~m} T c-H M P A O-l a b e l e d ~ m o n o c y t e s}$ were the liver and the spleen, followed by the kidneys, lungs, upper intestinal and gallbladder walls, and urinary bladder wall. The absorbed
TABLE 3

Number of Disintegrations (MBq-h/MBq)

\begin{tabular}{lc}
\hline \multicolumn{1}{c}{ Organ } & Mean \pm SD \\
\hline Total body & $6.960 \pm 0.159$ \\
Liver & $2.718 \pm 0.298$ \\
Spleen & $0.885 \pm 0.176$ \\
Lungs & $0.886 \pm 0.264$ \\
Red marrow & $1.058 \pm 0.216$ \\
Kidneys & $0.261 \pm 0.055$ \\
Urinary bladder & $0.422 \pm 0.048$ \\
Small intestine & $0.150 \pm 0.069$ \\
Upper large intestine & $0.194 \pm 0.090$ \\
Lower large intestine & $0.090 \pm 0.040$ \\
Thyroid & $0.011 \pm 0.016$ \\
Remainder of body & $0.286 \pm 0.329$ \\
\hline
\end{tabular}

doses per organ for women, compared with men, tended to be higher, with an effective dose of 0.010 and 0.013 $\mathrm{mSv} / \mathrm{MBq}$, respectively.

\section{DISCUSSION}

Cell labeling and imaging of cell trafficking in vivo becomes increasingly important in studies on immune-mediated inflammatory diseases such as RA (12). Monocyte-derived macrophages play an important role in the inflammatory cell infiltrate in RA and represent a significant target for therapeutic intervention (13). The development of new biologic therapies that specifically target monocyte migration may be assisted by in vivo imaging of monocyte migration to the inflamed joints. For this purpose, monocytes need to be isolated, purified, and subsequently labeled under good manufacturing practices (4). The relatively low number of monocytes available after isolation and purification requires a high-yield labeling procedure capable of labeling cells up to $10 \mathrm{~Bq} /$ cell, resulting in an injectable dose of $200-300 \mathrm{MBq}$ and enabling imaging with routine $\gamma$-cameras up to $20 \mathrm{~h}$ after reinjection.

Compared with labeled leukocytes, autologous monocytes labeled with ${ }^{99 \mathrm{~m}} \mathrm{Tc}-\mathrm{HMPAO}$ at high intracellular yields showed in vivo kinetics, with initial trapping in the lungs and subsequent distribution into the liver, spleen, and bone marrow (14). Accordingly, the fractional uptake of ${ }^{99 \mathrm{~m} T c-}$

TABLE 2

Percentage of 99mTc-HMPAO-Labeled Monocytes in Various Body Compartments over Time

\begin{tabular}{|c|c|c|c|c|c|}
\hline \multirow[b]{2}{*}{ Organ } & \multicolumn{5}{|c|}{ Percentage measured activity at... } \\
\hline & $10 \mathrm{~min}$ & $1 \mathrm{~h}$ & $2 \mathrm{~h}$ & $3 \mathrm{~h}$ & $20 \mathrm{~h}$ \\
\hline Lungs & $41.3 \pm 7.3$ & $18.2 \pm 3.6$ & $11.6 \pm 4.1$ & $7.8 \pm 3.3$ & $2.7 \pm 0.8$ \\
\hline Liver & $31.3 \pm 7.1$ & $37.9 \pm 5.5$ & $37.3 \pm 4.1$ & $35.5 \pm 3.1$ & $23.5 \pm 2.6$ \\
\hline Spleen & $6.9 \pm 1.5$ & $10.9 \pm 2.5$ & $12.4 \pm 3.1$ & $13.1 \pm 2.8$ & $4.3 \pm 1.3$ \\
\hline Bone marrow & $6.6 \pm 1.7$ & $11.3 \pm 2.8$ & $12.7 \pm 2.1$ & $14.3 \pm 2.6$ & $10.9 \pm 4.1$ \\
\hline Kidneys & $2.7 \pm 0.9$ & $3.4 \pm 1.2$ & $3.6 \pm 1.1$ & $3.5 \pm 1.1$ & $4.2 \pm 1.3$ \\
\hline Bladder & $2.1 \pm 0.9$ & $6.2 \pm 1.8$ & $1.7 \pm 0.4$ & $1.5 \pm 0.4$ & $0.6 \pm 0.3$ \\
\hline Intestines & 0 & 0 & 0 & $0.3 \pm 0.9$ & $5.5 \pm 2.6$ \\
\hline
\end{tabular}


TABLE 4

Radiation-Absorbed Dose Estimates for 99mTc-HMPAO-Labeled Monocytes

\begin{tabular}{|c|c|c|}
\hline \multirow[b]{2}{*}{ Organ } & \multicolumn{2}{|c|}{ Radiation-absorbed dose (mSv/MBq) } \\
\hline & Men & Women \\
\hline Adrenals & $0.0082 \pm 0.0002$ & $0.0091 \pm 0.0037$ \\
\hline Brain & $0.0005 \pm 0.0001$ & $0.0006 \pm 0.0003$ \\
\hline Breasts & $0.0019 \pm 0.0002$ & $0.0020 \pm 0.0007$ \\
\hline Gallbladder wall & $0.0108 \pm 0.0008$ & $0.0113 \pm 0.0047$ \\
\hline $\begin{array}{l}\text { Lower large } \\
\text { intestine wall }\end{array}$ & $0.0072 \pm 0.0020$ & $0.0069 \pm 0.0035$ \\
\hline Small intestine & $0.0065 \pm 0.0015$ & $0.0068 \pm 0.0033$ \\
\hline Stomach wall & $0.0055 \pm 0.0004$ & $0.0058 \pm 0.0024$ \\
\hline $\begin{array}{l}\text { Upper large } \\
\text { intestine wall }\end{array}$ & $0.0105 \pm 0.0031$ & $0.0105 \pm 0.0052$ \\
\hline Heart wall & $0.0048 \pm 0.0002$ & $0.0055 \pm 0.0022$ \\
\hline Kidneys & $0.0184 \pm 0.0028$ & $0.0179 \pm 0.0069$ \\
\hline Liver & $0.0314 \pm 0.0023$ & $0.0360 \pm 0.0139$ \\
\hline Lungs & $0.0141 \pm 0.0025$ & $0.0163 \pm 0.0064$ \\
\hline Muscle & $0.0023 \pm 0.0001$ & $0.0026 \pm 0.0010$ \\
\hline Ovaries & NA & $0.0045 \pm 0.0014$ \\
\hline Pancreas & $0.0098 \pm 0.0007$ & $0.0106 \pm 0.0044$ \\
\hline Red marrow & $0.0087 \pm 0.0014$ & $0.0079 \pm 0.0031$ \\
\hline Osteogenic cells & $0.0068 \pm 0.0008$ & $0.0079 \pm 0.0032$ \\
\hline Skin & $0.0010 \pm 0.0001$ & $0.0011 \pm 0.0005$ \\
\hline Spleen & $0.0755 \pm 0.0147$ & $0.0764 \pm 0.0325$ \\
\hline Testes & $0.0010 \pm 0.0001$ & NA \\
\hline Thymus & $0.0021 \pm 0.0002$ & $0.0023 \pm 0.0010$ \\
\hline Thyroid & $0.0077 \pm 0.0087$ & $0.0111 \pm 0.0113$ \\
\hline Urinary bladder wall & $0.0177 \pm 0.0019$ & $0.0266 \pm 0.0088$ \\
\hline Uterus & NA & $0.0044 \pm 0.0018$ \\
\hline Total body & $0.0038 \pm 0.0001$ & $0.0042 \pm 0.0017$ \\
\hline $\begin{array}{l}\text { Effective dose } \\
\text { equivalent } \\
\text { (mSv/MBq) }\end{array}$ & $0.0137 \pm 0.0005$ & $0.0168 \pm 0.0006$ \\
\hline $\begin{array}{c}\text { Effective dose } \\
\text { (mSv/MBq) }\end{array}$ & $0.0101 \pm 0.0003$ & $0.0125 \pm 0.0004$ \\
\hline
\end{tabular}

$\mathrm{NA}=$ not applicable

HMPAO-labeled monocytes in most major organs was similar to previously reported results using ${ }^{111} \mathrm{In}$-oxine- or 99m Tc-HMPAO-labeled white blood cells (WBCs) $(14,15)$. However, we observed higher retention of monocytes in the lungs and liver and lower accumulation in the spleen, compared with labeled WBCs. In some aspects, biodistribution of labeled monocytes resembled biodistribution of labeled macrophages, with higher liver accumulation (16).

All patients had active RA. Because monocytes migrate to inflamed joints, biodistribution could be slightly different in healthy volunteers or patients without active inflammation. However, the absolute amount of activity present in an inflamed joint was very low and did not exceed $0.1 \%$ of the total injected dose in these patients (17). Therefore, this result will not affect dosimetry calculations.

For calculation of absorbed doses of ${ }^{99 \mathrm{~m} T c-H M P A O-}$ labeled monocytes, the OLINDA/EXM software was used (10). This software was created as a replacement for the widely used MIRDOSE3.1, retaining most of the main functions of MIRDOSE3.1 with the addition of some new models including a kinetic input module with exponential curve fitting of the input data for determining the number of disintegrations per unit activity administered $(\mathrm{Bq}-\mathrm{h} / \mathrm{Bq})$ in each source organ (10).

Bone marrow activity was measured in lumbar vertebrae 2-4 and corrected for total bone marrow weight. Extrapolation of lumbar bone marrow uptake to total bone marrow uptake could possibly introduce an additional uncertainty. However, ROI-based assessment of total bone marrow uptake is not possible because of significant overlap of physiologic uptake in major organs. Therefore, this method is frequently used in labeled WBC dosimetry $(15,18)$.

The percentage of ${ }^{99} \mathrm{~m}$ Tc-HMPAO-labeled monocytes in the blood was measured in blood samples taken at different time points after reinjection. These values were not introduced in the OLINDA/EXM model because a significant overlap with blood activity measured in multiple organs on whole-body scintigraphy exists. In the OLINDA/EXM model, blood activity is accounted for in the value for the remainder of the body (10).

An overlap of activity in organs on whole-body scintigraphy was demonstrated. This occurred mainly in the lungs, liver, and kidneys. ROIs were carefully drawn to minimize overlap, but this procedure could not exclude all overlaps. Overlap of activity was also time-dependent, and data were carefully analyzed excluding or correcting measured data points containing obvious overlap artifacts.

Whole-body scintigraphy was performed at a speed of $8 \mathrm{~cm} / \mathrm{min}$ to allow sensitive imaging of a relatively limited dose of reinjected ${ }^{99 m} \mathrm{Tc}-\mathrm{HMPAO}-$ labeled monocytes. Because monocyte distribution is a dynamic process changing over time, an error could be introduced in organ quantification with a physical decay of ${ }^{99 m} \mathrm{Tc}$. However, major activity is retained in a relatively limited section of the body: in the thorax and the upper abdomen. Therefore, the decay correction was adjusted to the time of onset of the whole-body scan plus an additional $10 \mathrm{~min}$ to focus on the major uptake organs.

The radiation-absorbed estimates for ${ }^{99 \mathrm{~m} T c-H M P A O}$ labeled monocytes, compared with stabilized ${ }^{99 \mathrm{~m}} \mathrm{Tc}-$ HMPAO-labeled WBCs (14), were a fraction higher but comparable with ${ }^{99 \mathrm{~m}} \mathrm{Tc}-\mathrm{HMPAO}-$ labeled granulocytes (19) and the effective dose published in ICRP Publication 62 (20).

\section{CONCLUSION}

99m Tc-HMPAO-labeled monocytes have biodistribution and radiation dosimetry similar to those of ${ }^{99 \mathrm{~m}} \mathrm{Tc}-\mathrm{HMPAO}-$ labeled mixed WBCs and can therefore be used for in vivo monitoring of monocyte migration in patients with RA.

\section{ACKNOWLEDGMENTS}

We thank the staff of the Laboratory for Stem Cell Transplantation at Sanquin Research and the staff of the Department of Nuclear Medicine and Radiopharmacy at the AMC for their technical assistance. We thank Frederique 
Cavelaars for her assistance with analyzing the image data and Mike Stabin for assistance with the OLINDA/EXM model.

\section{REFERENCES}

1. Tak PP. Chemokine inhibition in inflammatory arthritis. Best Pract Res Clin Rheumatol. 2006;20:929-939.

2. Tak PP. Effects of infliximab treatment on rheumatoid synovial tissue. J Rheumatol Suppl. 2005;74:31-34.

3. Haringman JJ, Kraan MC, Smeets TJ, Zwinderman KH, Tak PP. Chemokine blockade and chronic inflammatory disease: proof of concept in patients with rheumatoid arthritis. Ann Rheum Dis. 2003;62:715-721.

4. van Hemert FJ, Thurlings R, Dohmen SE, et al. Labeling of autologous monocytes with 99mTc-HMPAO at very high specific radioactivity. Nucl Med Biol. 2007;34:933-938.

5. van Hemert FJ, van LH, Schimmel KJ, van Eck-Smit BL. Preparation, radiochemical purity control and stability of ${ }^{99 \mathrm{~m}}$ Tc-mertiatide (Mag-3). Ann Nucl Med. 2005;19:345-349.

6. National Electrical Manufacturers Association. Performance Measurements of Scintillation Cameras. Washington, DC: National Electrical Manufacturers Association; 1994. NEMA Standards Publication NU 1-1994.

7. Du Bois D, Du Bois EF. A formula to estimate the approximate surface area if height and weight be known. Arch Intern Med. 1916;17:863-871.

8. Brown E, Hopper J, Hodges JL, Bradley B, Wennesland R, Yamauchi H. Red cell, plasma, and blood volume in the healthy women measured by radiochromium cell-labeling and hematocrit. J Clin Invest. 1962;41:2182-2190.

9. Wennesland R, Brown E, Hopper J, et al. Red cell, plasma and blood volume in healthy men measured by radiochromium (Cr51) cell tagging and hematocrit: influence of age, somatotype and habits of physical activity on the variance after regression of volumes to height and weight combined. J Clin Invest. 1959;38:1065-1077.
10. Stabin MG, Sparks RB, Crowe E. OLINDA/EXM: the second-generation personal computer software for internal dose assessment in nuclear medicine. J Nucl Med. 2005;46:1023-1027.

11. International Commission on Radiological Protection (ICRP). Report of the Task Group on Reference Man. Oxford, U.K.: Pergamon Press; 1975. ICRP publication 23.

12. McQueen FM, Ostergaard M. Established rheumatoid arthritis: new imaging modalities. Best Pract Res Clin Rheumatol. 2007;21:841-856.

13. Tak PP. Examination of the synovium and synovial fluid. In: Firestein GS, Panayi GS, Wollheim FA, eds. Rheumatoid Arthritis. Frontiers in Pathogenesis and Treatment. New York, NY: Oxford University Press, Inc.; 2000:55-68.

14. Robins PD, Salazar I, Forstrom LA, Mullan BP, Hung JC. Biodistribution and radiation dosimetry of stabilized ${ }^{99 \mathrm{~m}} \mathrm{Tc}$-exametazine-labeled leukocytes in normal subjects. J Nucl Med. 2000;41:934-940.

15. Forstrom LA, Dunn WL, Rowe FA, Camilleri M. ${ }^{111}$ In-oxine-labelled granulocyte dosimetry in normal subjects. Nucl Med Commun. 1995;16:349-356.

16. Quillien V, Moisan A, Lesimple T, Leberre C, Toujas L. Biodistribution of ${ }^{111}$ indium-labeled macrophages infused intravenously in patients with renal carcinoma. Cancer Immunol Immunother. 2001;50:477-482.

17. Thurlings R, Bennink RJ, Dohmen SE, Wijbrants C, Tak PP. Dynamics of monocyte migration to the synovium: development of ${ }^{99 \mathrm{~m}} \mathrm{Tc}-\mathrm{HMPAO}$ scintigraphy [abstract]. Ann Rheum Dis. 2006;65(suppl 1):A42.

18. Forstrom LA, Dunn WL, Mullan BP, Hung JC, Lowe VJ, Thorson LM. Biodistribution and dosimetry of $\left[{ }^{18} \mathrm{~F}\right]$ fluorodeoxyglucose labelled leukocytes in normal human subjects. Nucl Med Commun. 2002;23:721-725.

19. Roddie ME, Peters AM, Danpure HJ, et al. Inflammation: imaging with Tc- $99 \mathrm{~m}$ HMPAO-labeled leukocytes. Radiology. 1988;166:767-772.

20. International Commission on Radiological Protection. ICRP Publication 62: Radiological protection in biomedical research. A report of Committee 3 adopted by the International Commission on Radiological Protection. Ann ICRP. 1991; 22:1-28. 